\title{
The development of diagnostics methodological principles of the railway rolling stock on the basis of the analysis of dynamic vibration processes of the rail
}

\author{
Juraj Gerlici ${ }^{1}$, Olena Nozhenko ${ }^{1, *}$, Ganna Cherniak $^{2}$, Mykola Gorbunov ${ }^{2}$, \\ Rostyslav Domin ${ }^{2}$, Tomáš Lack ${ }^{1}$ \\ ${ }^{1}$ University of Žilina, Faculty of Mechanical Engineering, Department of Transport and Handling \\ Machines, 01026 Žilina, Slovak Republic \\ ${ }^{2}$ Volodymyr Dahl East Ukrainian National University, Department of Rail Transport, 93400 \\ Sewerodonetsk, Ukraine
}

\begin{abstract}
The paper discusses the preconditions of the methodology development of diagnosis system for assessing dynamic impact of the rolling stock on the basis of processing and analysis of data obtained in operation on the results of measurement of parameters that characterize dynamic vibration processes of the mechanical system of "rolling stock - track". On the basis of usage of the processing methods of time series and stochastic processes there has been established the relationship between these dynamic processes and wheel defects, and designed experimental data processing algorithms, which in the future will be an integral part of the intellectual systems of decision making when assessing the impact level of the rolling stock on the track. The article presents some results of the experimental and theoretical research of the rail accelerations data, which have been registered during passing of the train. The computational algorithm of the specialized pre-processing of the multidimensional signal recorded by this system is described. The advantage of this algorithm is that it does not require additional information about the train speed on the section equipped with the monitoring system, about the number of wheel pairs of locomotives and train cars, and about the distances between the wheel pairs. Based on the processing results of accelerations of the rails there have been set the parameters of increase in all statistical indicators with increase in the train speed. It is noted that the level of indicators for accelerations of the rails in the vertical direction is twice as high as the corresponding parameters in the horizontal direction.
\end{abstract}

Keywords: rolling stock with the wheels defects; acceleration of the rails; the statistical signal processing techniques; the calculation algorithm

\footnotetext{
* Corresponding author: juraj.gerlici@fstroj.uniza.sk

Reviewers: Grzegorz Domek, Alžbeta Sapietová
} 


\section{Introduction}

The modern systems of monitoring of the dynamic condition of vehicles intended to detect faults fundamentally use concepts and hypothesis, which are based on in-depth filtration methods and the time series analysis [1]. The practical implementation of such systems is carried out on the basis of evaluation of the dynamic behavior of both the rolling stock [2-6] and the track structure during passing of the train [7-9].

Currently, most of the commercial products for monitoring the railway vehicles condition are focused on the bogie system, which is due to the fact that some of its most important components are exposed to rapid change of their technical condition and have a serious impact on operability of the system "railway vehicle - railway" in whole and movement safety in particular. In such a case the key aspect is the ability of the existing monitoring technology to detect the diagnostic parameters in real time and to assess and predict the technical maintenance time [1].

The modern monitoring systems, which are installed on the track, were analyzed by Brickle B etc. [9] commissioned by the The Rail Safety and Standard Board (RSSB) UK and have been classified by the functional categories, where as a separate group there has been allocated the wheel impact load detectors (WILD), which detect the presence of a defective wheel by measuring the magnitude of the load (amount of force the wheel exerts to the rail) and comparing it to the specified threshold.

The instrumental basis of the monitoring systems can be optical sensors, accelerometers, load sensors or strain gauges. The available systems in market are GE Transportation's MATTILD, DeltaRail's Wheelchex, Teknis' WCM and Salient System's WILD [1]. However, according to authors [1,9], these systems are not that reliable and in most cases the inspection of railway vehicles takes place in the depot before it leaves for operation. Such inspections are time-consuming and prone to human error. These techniques have been around for many years, but an increase in damaged wheelset due to higher speeds, heavier loads and modified operating conditions has led the rail stakeholders to re-evaluate these inspections strategies. A difficulty for such systems is to determine the threshold limit values of the measured magnitude which characterizes the force the wheel exerts to the rails.

And, if the threshold limit values of stresses on the rail base are standardized [10], then there arise dome difficulties concerning justification of the thresholds limit values of accelerations of the rail or the data for optical sensors under conditions of the necessity to assess different types of the rolling stock, the axle loads and the technical conditions with availability of only the output signal.

For countries with a gauge of $1520 \mathrm{~mm}$, where the quality of technical maintenance and used design of the rolling stock (for example, a large unsprung weight of freight cars on the bogies of model 18-100) create additional risks of occurrence of limit-exceeding impact of the rolling stock on the track, there is an acute problem of development and implementation of a new method to monitor workloads affecting the track structure during passing of freight cars. In Ukraine, the work in this direction started in 2010. It envisages creation of a method of monitoring which is based on accelerations of elements of the track structure as magnitudes that do not require creation of specific measurement conditions (as opposed to the methods of stress freezing). This article presents the results of experimental research on impacts on the track structure of freight cars with the use of the given method of monitoring. 


\section{Description of the experimental monitoring system and its testing conditions}

At the moment in the countries with a gauge of $1520 \mathrm{~mm}$ the existing regulations for assessing dynamic influence of the new and modernized rolling stock on the track are regulated by normative documents [10] and include assessment of the stress-deformed states of the rails under influence of the rolling stock, based on the recording of the stress in the cross section elements of the rail by using strain gauges (fig. 1, a). The admissibility of the stress magnitudes (edge stresses) and forces arising in the rails in the vertical and horizontal directions are estimated basing on the maximal possible values for these parameters as set out in [10].

Assessment of the dynamic impact of the rolling stock on the rails using accelerometers that underlies the developed method for monitoring of work loads is complicated by absence of threshold limit values of acceleration of the rail. These magnitudes characterize the maximum permissible value of influence of the rolling stock on the rail track that provides the permissible technical condition of the track and the level of accumulation of changes in the parameters subjected to control, for the period between two scheduled inspections during passing of the track geometry car. The proposed system is based on measuring acceleration of the rails due to the train passing the way section equipped with the sensors system [11]. It uses two-axle accelerometers with measuring acceleration range up to $700 \mathrm{~m} / \mathrm{s}^{2}$ in the vertical direction and up to $350 \mathrm{~m} / \mathrm{s}^{2}$ in the horizontal one; the error is up to $10 \%$. It's made based on the chip ADXL278. The accelerometers are installed on the bases of the rails (fig. 1, b) symmetrically on both rail threads. The software that implements synchronization, the data collection and storage of the measured accelerations is implemented on LabView platform.

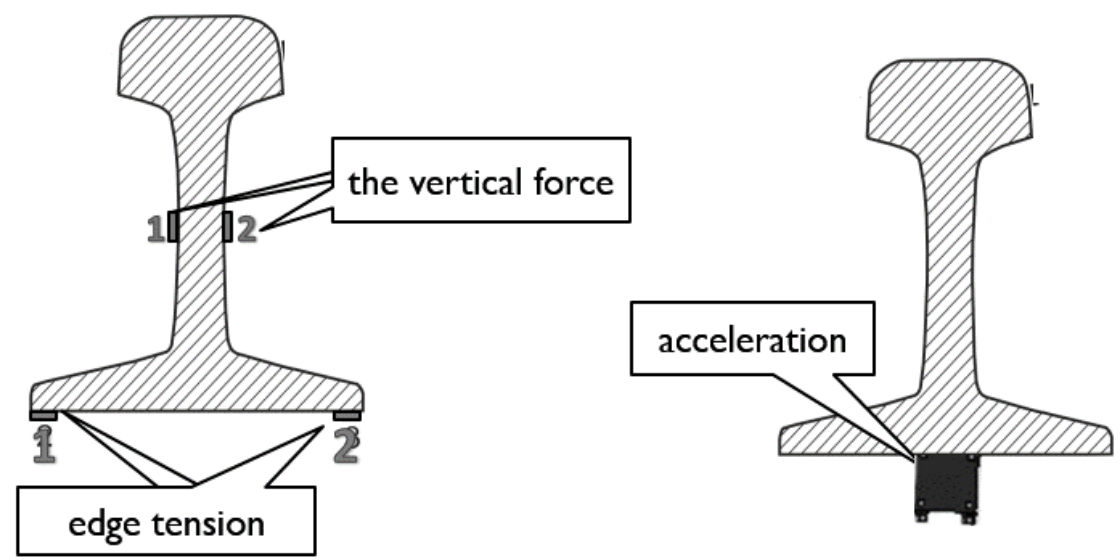

Fig. 1. Scheme of sensors location in the measuring section of the rail to assess workloads of the rolling stock on the track in accordance with [12] (a) and implemented during research conduction (b)

Comparative testing to assess the impact of the rolling stock on the rail were carried out along a straight section equipped with two measuring systems - standardized system according to DSTU 7571: 2014 (Fig. 1, a) [12] and the proposed system (Fig. 1, b.) [13]. Experimental section had rails of type R65, ferroconcrete sleepers (1840 units $/ \mathrm{km}$ ) with stone ballast. 8 cross sections of the rails (Fig. 2) were equipped with sensors in the space between the sleepers with the distance between the cross sections of about $545 \mathrm{~mm}$. 


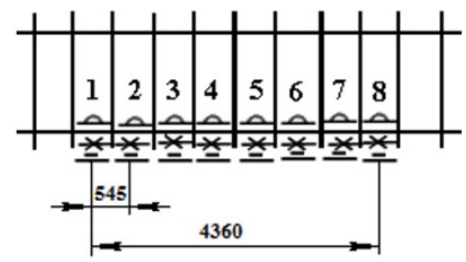

a)

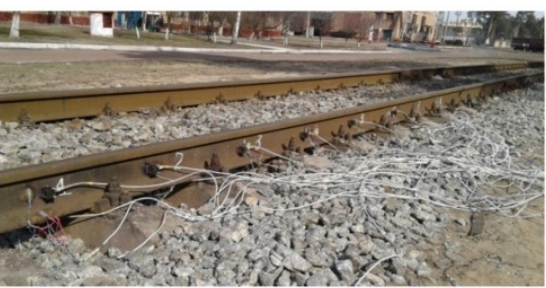

b)

$\rightarrow-$ a device for measuring of vertical force; $\boldsymbol{\varrho}$ - device for measuring the stresses in the edge of the rail flange; $\boldsymbol{Z}_{-}$a device for measuring acceleration rails

Fig. 2. Experimental section, equipped with sensors: a) scheme; b) photo

Tests involved an experimental train consisting of a locomotive of the model CHME3 and a gondola car in an empty $(20.5 \mathrm{t})$ and loaded ( $79 \mathrm{t})$ states. The gondola car had defects on the rolling surface ( 1 wheelset without defects, 2 wheelset with the slid flat with depth of $h_{2}=0,5 \mathrm{~mm}, 3$ wheelset with the slid flat with depth of $h_{3}=2,5 \mathrm{~mm} 4$ wheelset with the slid flat $h_{4}=1 \mathrm{~mm}$ ). Experimental trips were carried at a constant rate, which varied in the range of $v=10 \div 40 \mathrm{~km} / \mathrm{h}$, with an interval of $\Delta v=5 \mathrm{~km} / \mathrm{h}, 6$ trips $(l=1 \div 6)$ with each speed in empty and loaded states. The sampling frequency of the accelerometers and the strain gauges was $400 \mathrm{~Hz}$.

The aim of the test was to compare the magnitudes of stresses in the rails during passing of the rolling stock with accelerations of the rail for establishing relationships between the fixed magnitudes, the rolling stock parameters and test conditions (the speed, the load of rolling stock, the wheel defects) and assessment of dynamic impact of the rolling stock with defective wheel sets by statistical methods.

\section{Analysis of the dynamic impact of an experimental train on the track structure}

The processing procedure of the experimental data obtained during measurement by the strain gages, was performed by statistical methods in accordance with [12], and data, obtained using accelerometers, - following the procedure described in [13]. In this case, the magnitudes of edged stresses were compared (the signal example is shown in Fig. 3a) and acceleration of the rails (the signal example is shown in Fig. 3b). The initial comparison of the signals showed clear advantages of the data processing that record edged stresses, and characterize a low frequency process which does not require the special processing algorithms.
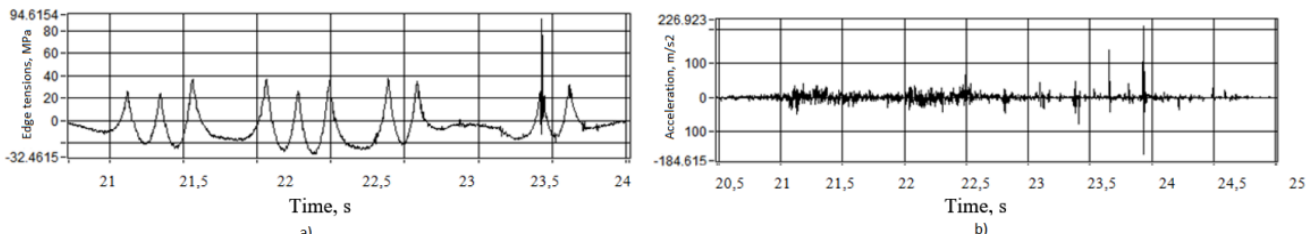

Fig. 3. Records of signals, fixing edged stresses (a) and acceleration (b) of the rails at $\mathrm{v}=30 \mathrm{~km} / \mathrm{h}$ in the vertical direction when passing of the experimental train with loaded gondola car through the third sensor

In the first stage of the signals processing there has been set a task to establish the impact of the movement speed on the magnitude of dynamic impact of the experimental train on the rail, which was assessed by the magnitude of the edge stresses of the rails according to standard procedures and magnitudes of acceleration of the rails based on the proposed methodology. For the separation of the multidimensional signal $\mathrm{S}$ into segments 
associated with individual wheels in the automatic mode, there has been developed a computational algorithm consisting of these steps:

- decomposing signal $S$ into three parts $S=S^{\prime} \cup S^{\prime \prime} \cup S^{\prime \prime \prime}$, where parts $S^{\prime}, S^{\prime \prime}, S^{\prime \prime \prime}$ correspond to measurements before the train passing, during passing and after passing of the train over the sensors. The informative part of the signal processing component is $S^{\prime \prime}$ for which an iterative procedure is applied using the cost function;

- filtrating signal $S^{\prime \prime}$ using the methodology of wavelet compression with a nonparametric noise removal using the Waveshrink function;

- building the envelopes eSi" using Gilbert transformations for all components of the multidimensional signal;

- building reciprocal correlation functions for the envelopes $e S i^{\prime \prime}$ of the same type of signals and calculating the shift between signals received from different sensors on this basis;

- displacing the envelopes of signals from different sensors in a position corresponding to the signal from the first sensor and forming the summary signal (for signals of the same type), which allows to find segments associated with the individual wheels.

It should be noted that the developed algorithm does not require input information on the speed of the train on the section, equipped with the monitoring system, and the distances between the wheel pairs of the train. The magnitudes of these parameters are calculated in the process of the algorithm operation.

After envelope segments have been allocated for the all multidimensional signals, maximum values have been calculated for each segment, on the basis of which the statistical samples for processing are formed. Performed statistical processing includes grouping of the samples in the vertical $Z$ and the horizontal $Y$ direction for the left $\mathrm{L}$ and right $R$ rails, which in the result provide selection of four main groups of samples $Z R, Z L$, $Y R, Y L$. In this case, each basic group contains samples comprising the maximum accelerations for all wheel sets $w=1, \ldots, 20$ and all the way sections $m=1, \ldots, 15$. The obtained samples are checked for compliance with the normal distribution law by assessing the sample uniformity using the coefficient of variation, which by the analogy with [10] should be less than $0.4(40 \%)$. After checking the samples on normality, statistical indicators are calculated for them, namely, the magnitudes of expectation, standard deviation, and probable maximum values $\max _{a} Z R, \max _{p r} Z L, \max _{p r} Y R, \max _{p r} Y L$. In more detail the algorithm of processing the acceleration of the rails is presented in [13].

Comparison of the statistical parameters of the researched magnitudes of stresses and accelerations of the rails during passing of the shunting locomotive and the loaded gondola car has showed that the speed in the range of $10 \ldots 40 \mathrm{~km} / \mathrm{h}$ had no significant effect on the magnitudes of the statistical parameters of the rails edge stresses. In contrast to stresses, the magnitude of the rail acceleration during passing of the shunting locomotive and loaded gondola car is linearly dependent on the movement speed. The resulting dependences of the rails accelerations on the magnitude of the movement speed of the rolling stock is qualitatively consistent with the results of tests [13], where there was also observed a linear dependence of possible maximum acceleration values on the movement speed in the range of $40 \ldots 130 \mathrm{~km} / \mathrm{h}$ during passing of a two-axle locomotive CHS8. Moreover, it was found out that several times exceeding of the permissible value of the magnitude max $\sigma$ for $3^{\text {rd }}$ wheel gondola car (reaches up to $790 \mathrm{MPa}, h_{3}=2,5 \mathrm{~mm}$ ) for speeds of $20-40 \mathrm{~km} / \mathrm{h}$ for individual passing, which is $240 \mathrm{MPa}$ for all types of the rolling stock [12,13]. In addition, such exceeding is observed for all the other wheels of the gondola car at individual speeds for individual passing. Considering the impact of the gondola car movement speed on the rails acceleration, there has been found increase in magnitudes of statistical characteristics for $9^{\text {th }}\left(h_{3}=2,5 \mathrm{~mm}\right)$ and $10^{\text {th }}\left(h_{4}=0 \mathrm{~mm}\right)$ wheel setsof the experimental train in both directions. Moreover, the range of changing of maximum possible values of edge stress of 
the rail $\max _{\sigma}$ and maximum possible values of the rails acceleration which arise during passing of the rolling stock $\max _{a}$ in a range of speeds of $10-40 \mathrm{~km} / \mathrm{h}$, presented in Fig. 4, clearly shows an abnormal magnitudes both for the rails acceleration and for edge stresses, which occur during passing of the gondola car wheel sets with wheels defects compared with the values of the same parameters arising during passing of the locomotive CHME3. At the same time the parameters considered in the vertical direction are illustrative, which, in comparison with the horizontal direction, more clearly show increased impact of the wheel sets of the gondola car. Assessment of the dependence $\max _{\sigma}$ on the magnitude $\max _{a}$ (Fig. 5) in the investigated range of speeds has demonstrated abnormal magnitudes of the rails acceleration during passing of the 6th wheel set of the locomotive (Fig. 5a) without exceeding the permissive level of stress $(240 \mathrm{MPa})$, and that the level of acceleration exceeding $330 \mathrm{~m} / \mathrm{s}^{2}$ for $3^{\text {rd }}$ and $4^{\text {th }}$ wheel sets of the gondola is probably abnormal (Fig. $5 \mathrm{~b}$ ).

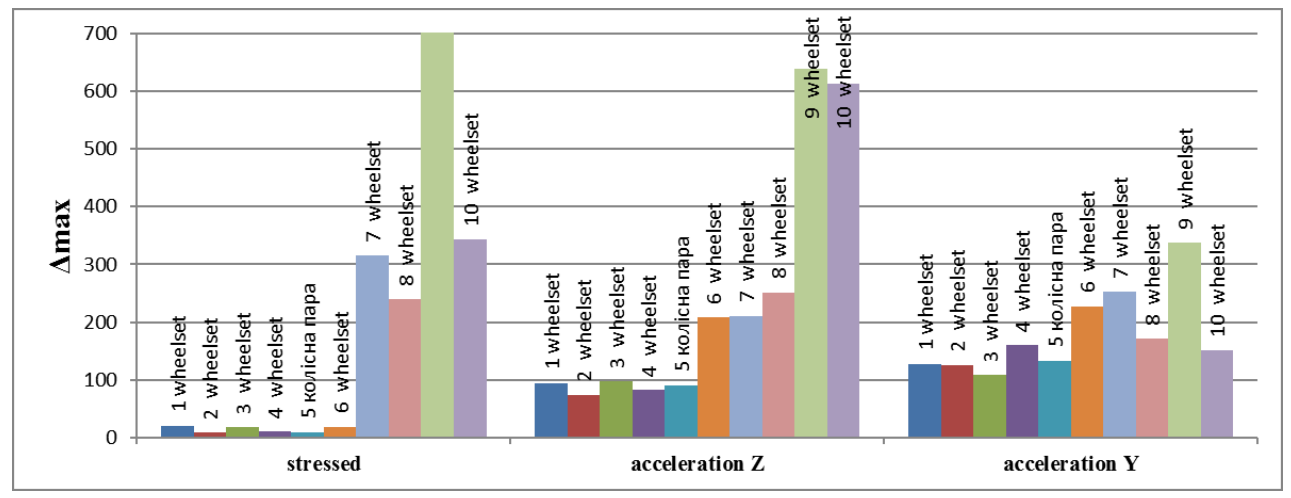

Fig. 4. The range of changes $\max _{\sigma}$ and $\max _{a}$ at $\mathrm{v}=10 \div 40 \mathrm{~km} / \mathrm{h}$ for all wheel sets of the experimental train

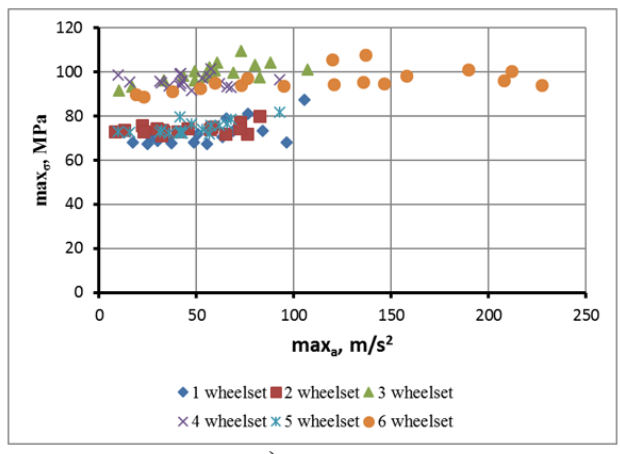

a)

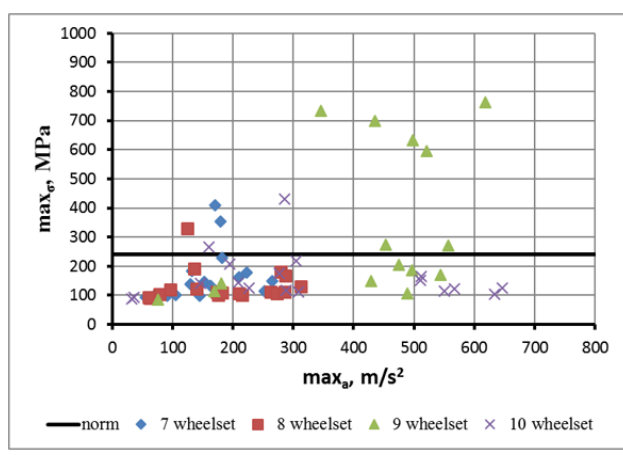

b)

Fig. 5. Dependence of $\max _{\sigma}$ and $\max _{a}$ in the vertical direction in the tested speed range for the wheel setsof the locomotive a) and the gondola car b)

\section{Conclusion}

The method for monitoring workloads of the existing rolling stock on the track structure is proposed. The developed method is based on measuring accelerations of the rails in the vertical and horizontal transverse directions. The necessary measurements are carried out on the selected track section using two-axial accelerometers installed symmetrically on the 
bases of the rails between the sleepers on the right and left sides of the track structure. In contrast to the method of measuring the stress and the forces, which currently being used to assess the impact of the rolling stock on the rails for the railways with a track of $1520 \mathrm{~mm}$, this method does not require creation of special conditions for measurement. The total number of accelerometers installed on certain sections of track crossings with a fixed step, depends on the purpose of monitoring and characteristics of the track structure. During passing of the train on the of test section multi-dimensional signals with a number of components equal to doubled number of accelerometers are registered. The article presents the results of the field testing of the system carried out in the track section, which was equipped with accelerometers in 8 measurement cross sections, and comparison of the results with the standard method for determining the impact of the rolling stock on the rail by identifying the stress in the rails. For experimental research there has been used experimental train consisting of the shunting locomotive CHME3 and the gondola car. The train passed through the experimental section in forward and reverse directions at speeds from 10 to $40 \mathrm{~km} / \mathrm{h}$ with an interval of $5 \mathrm{~km} / \mathrm{h}$.

Comparison of the statistical parameters of the stress of the rails and of acceleration during passing of the shunting locomotive showed that the speed in the range of $10 \ldots 40$ $\mathrm{km} / \mathrm{h}$ had no significant effect on statistical parameters of magnitudes of edge stress of the rails both during passing of the empty gondola car and the loaded one, the maximum possible value of which varies in the range of $\max _{\sigma}=66 \ldots 106 \mathrm{MPa}$. Interesting information can be found in $[14,15,16]$. In contrast to stresses, the magnitude of the rails acceleration during passing of the shunting locomotive is linearly dependent on the speed. This trend is observed in both the vertical (magnitude $\max _{a} Z$ reaches $227 \mathrm{~m} / \mathrm{s}^{2}$ ), and the horizontal (magnitude $\max _{a} Y$ reaches $283 \mathrm{~m} / \mathrm{s}^{2}$ ) directions.

Analysis of statistical parameters of stresses of the rails and accelerations during passing of the gondola car has showed several times exceeding of the permissible value of the max $\sigma$ for all wheels of the loaded gondola car at individual speeds.

The research was held within the framework of National Scholarship Programme of the Slovak Republic for the support of mobility of students, PhD students, university teachers, researchers and artists and on the basis of the scientific research "Development of the scientific principles of diagnostics of mechanical transport systems on the basis of the analysis of dynamic oscillation processes of their elements", funded by the Ministry of Education and Science of Ukraine.

\section{References}

1. R. Ngigi, A. Pislaru Crinela Bal, G. Fengshou, Modern techniques for condition monitoring of railway vehicle dynamics. J. of Physics: Conference Series 364 (2012)

2. C. Ward, P. Weston, E. Stewart, H. Li, R. Goodall, C. Roberts, T. Mei, G. Charles, R. Dixon, Condition monitoring opportunities using vehicle-based sensors. Proc. Inst. of Mech. Eng. Part F: J. of Rail and Rapid Transit 225 (2), 202-218 (2011)

3. T. Mei, H. Li, Measurement of vehicle ground speed using bogie-based inertial sensors. Proc. of the Inst. of Mech. Eng. Part F: J. of Rail and Rapid Transit 222 (2), 107-116 (2008)

4. P. Monje, G. Martinez, B. Aranguren, L. Casado, Using bogie-mounted sensors to measure wheel rolling and sliding in railway tracks. Proc. of the Inst. of Mech. Eng. Part F: J. of Rail and Rapid Transit (2011)

5. A. Matsumoto, Y. Sato, H. Ohno. et al., A new measuring method of wheel-rail contact forces and related considerations. Wear 265 (9-10), 1518-1525 (2008) 
6. S. Bleakely, S. Senini, Autonomous time frequency analysis of wagon body accelerations. Proc. of the V Asia Pacific Industrial Engineering and Management Systems Conference Gold Coast Australia, 34.6.1-34.6.12 (2004)

7. Bogie Condition Monitoring. Extract from the Railway technical handbook 1, 152-163

8. A. Mostovych, A. Cherniak, O. Nozhenko, Application of the methods of correlation and spectral analysis for processing the results of dynamic testing of railway rolling stock. Railway transport of Ukraine 4 (113), 20-24 (2015)

9. T. Moynihan, G. English, Railway safety technologies. Canada Research and traffic group (2007)

10. A. Wei, Q. Xin, W. Chung, S. Liu, H. Tam, S. Ho, Real-time train wheel condition monitoring by fiber bragg grating sensors. Int. J. of Distributed Sensor Networks 2012, 1-7 (2012)

11. B. Brickle, R. Morgan, E. Smith, J. Brosseau, C. Pinney, Identification of existing and new technologies for wheelset condition monitoring: Report for Task T607. TTCI Ltd UK RSSB (2008)

12. DSTU 7571:2014 Rolling railways. The norms of permissible impact on railway track $1520 \mathrm{~mm}$.

13. G. Chernyak, J. Gerlici, O. Nozhenko, R. Domin, K. Kravchenko, T. Lack, The experimental research of the dynamic loading of the railway track. III ročník konference pro mladé vědecké pracovníky "Experimentální a výpočtové metody v inženýrství" (2016)

14. A. Sapietová, M. Sága, P. Novák, R. Bednár, J. Dižo, Design and application of multisoftware platform for solving of mechanical multi-body system problems. Mechatronics: Recent technological and scientific advances, 345-354 (2011)

15. M. Sága, R. Bednár, M. Vaško, Contribution to modal and spectral interval finite element analysis. Vibration Problems ICOVP 2011, Springer Proceedings in Physics 139, 269-274 (2011)

16. P. Pecháč, M. Sága, Controlling of local search methods' parameters in memetic algorithms using the principles of simulated annealing. Proc. Eng. 136, 70-76 (2016) 